\title{
Structural and Mössbauer Spectral Studies of Nanosized Aluminum Doped Manganese Zinc Ferrites
}

\author{
R. L. Dhiman, ${ }^{1}$ S. P. Taneja, ${ }^{2}$ and V. R. Reddy ${ }^{3}$ \\ ${ }^{1}$ Post-Graduate Department of Applied Physics, S.D. College, Ambala Cantt 133 001, India \\ ${ }^{2}$ Department of Physics, Maharshi Dayanand University, Rohtak 124 001, India \\ ${ }^{3}$ UGC-DAE Consortium for Scientific Research, University Campus, Khandwa Road, Indore 452 017, India
}

Correspondence should be addressed to R. L. Dhiman, roshandhiman_kuk@yahoo.co.in

Received 3 July 2008; Revised 23 September 2008; Accepted 16 November 2008

Recommended by Mohindar Seehra

\begin{abstract}
Nanoparticles of aluminum-substituted manganese zinc ferrites, $\mathrm{Mn}_{1.05} \mathrm{Zn}_{0.05} \mathrm{Al}_{x} \mathrm{Fe}_{1.9-x} \mathrm{O}_{4}$ with $0.4 \leq x \leq 1.0$ were synthesized by solid-state reaction route and characterized by XRD, TEM, and Mössbauer spectroscopy measurements. The particle size is found to very from 46 to $28 \mathrm{~nm}$ with increase of aluminum ions concentration. The unit cell parameter " $a_{O}$ " is found to decrease linearly with aluminum ions concentration due to smaller ionic radius of aluminum. The cation distributions were estimated from X-ray diffraction intensities of various planes. The theoretical lattice parameter, bulk density, porosity, X-ray density, oxygen positional parameter, ionic radii, jump length, as well as bonds and edges lengths of the tetrahedral (A-) and octahedral (B-) sites were determined. ${ }^{57} \mathrm{Fe}$ Mössbauer spectra recorded at room temperature were fitted with two sextets corresponding to $\mathrm{Fe}^{3+}$ ions at tetrahedral (A-) and octahedral (B-) sites. The magnetic hyperfine fields at A- and B-sites show a gradual decrease with increase of $\mathrm{Al}^{3+}$ ion concentration, which has been explained on the basis of supertransferred hyperfine field. The cation distribution obtained from X-ray intensities and Mössbauer data indicates a decrease in $\mathrm{Fe}^{3+}(\mathrm{B}) / \mathrm{Fe}^{3+}(\mathrm{A})$ ratio with increasing aluminum concentration thereby suggesting a decrease in ferrimagnetic behavior.
\end{abstract}

Copyright ( 2008 R. L. Dhiman et al. This is an open access article distributed under the Creative Commons Attribution License, which permits unrestricted use, distribution, and reproduction in any medium, provided the original work is properly cited.

\section{Introduction}

Nanoparticles of manganese zinc ferrites exhibit some unusual properties, for example, enhanced coercivity, modified saturation magnetization, super paramagnetism, and metastable cation distributions [1]. These nanoparticles have wide applications in heat transfer devices, drug delivery systems, and medical diagnostics, that is, especially in cancer treatment, and so forth $[2,3]$. Mn- $\mathrm{Zn}$ ferrites possess a spinel structure in which $\mathrm{Mn}^{2+}, \mathrm{Zn}^{2+}$, and $\mathrm{Fe}^{3+}$ cations are distributed among two interstitial tetrahedral (A-) and octahedral (B-) sites. In general, spinels are classified as normal, inverse, and mixed. In most cases, $\mathrm{Mn}^{2+}$ ions tend to occupy the octahedral B-sites and produce an inverse spinel structure. In normal spinel structure, $\mathrm{Zn}^{2+}$ ions prefer to hold the tetrahedral A-sites position. Although the Mn$\mathrm{Zn}$ ferrites have mixed spinel structure, the magnetic and electronic properties of these ferrites are dependent of their chemical composition, method of preparation, grain size, and distribution of cation between two interstitial sites [4-6]. The structural and the magnetic environments of these two sites are quite different. The substitutions of nonmagnetic ions, for example, $\mathrm{Al}^{3+}$ ions in simple and mixed ferrites have received a great deal of attention over the past few years [79]. It has been reported that the presence of nonmagnetic ions reduces the magnetic interactions between the two interstitial sites, causes decrease in hyperfine magnetic fields, and hence changes the magnetic and electronic properties. These effects are particularly apparent in the Mössbauer studies $[10,11]$. In recent years, researches on spinel ferrites have received great interest due to availability of new and sophisticated techniques for the synthesis and characterization of nanoparticles. Presently, the ferrites nanoparticles of average diameter $7 \mathrm{~nm}$ and $20 \mathrm{~nm}$ were synthesized by doping titanium and gallium ions, respectively, using solidstate reaction technique $[12,13]$. In the present work, aluminum substituted manganese zinc ferrites nanoparticles have been synthesized via solid-state reaction route. In order 


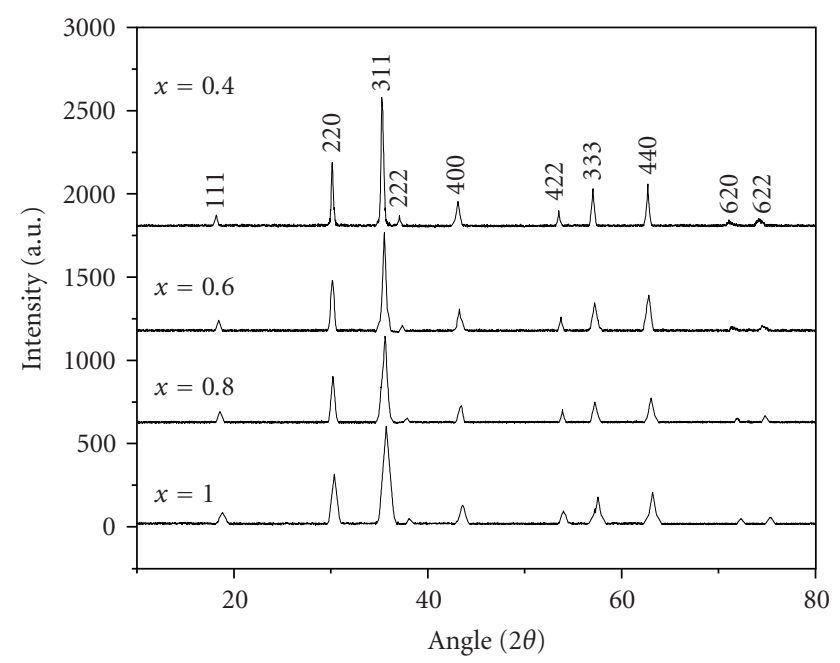

Figure 1: X-ray diffraction pattern of $\mathrm{Mn}_{1.05} \mathrm{Zn}_{0.05} \mathrm{Al}_{x} \mathrm{Fe}_{1.9-x} \mathrm{O}_{4}$ system.

to determine the cation distribution in the ferrite system understudy XRD, Mössbauer and TEM measurements have been carried out.

\section{Experimental}

Samples of the mixed spinel ferrites $\mathrm{Mn}_{1.05} \mathrm{Zn}_{0.5} \mathrm{Al}_{x} \mathrm{Fe}_{1.9-x} \mathrm{O}_{4}$ for $x=0.4,0.6,0.8$, and 1.0 were synthesized by using standard solid-state reaction technique. The required compositions were weighed and mixed in a mortar and pestle for 2 hours with acetone. The mixed powders were calcinated in air by raising temperature up to $200^{\circ} \mathrm{C}$ at the rate of about $5^{\circ} \mathrm{C} / \mathrm{min}$ and then up to $600^{\circ} \mathrm{C}$ in 60 minutes and allowed to cool to room temperature; finally the temperature was raised to $1000^{\circ} \mathrm{C}$ in 10 hours and slowly cooled to room temperature at a rate of $2^{\circ} \mathrm{C} / \mathrm{min}$. The reacted materials were well grounded in an agate mortar and pestled by adding a few drops of acetone again to reduce the particle size. To ensure their single-phase nature, the powder X-ray diffraction studies were made on Rigaku X-ray diffractometer by using $\mathrm{Cu}-\mathrm{K}_{\alpha}$ radiation of $1.54060 \AA$. The particle morphology was examined by transmission electron microscope model Hitachi H-7500. ${ }^{57} \mathrm{Fe}$ Mössbauer absorption spectra were recorded in transmission geometry at room temperature using a multichannel analyzer with a drive in constant acceleration mode. $\mathrm{A}{ }^{57} \mathrm{Co}(\mathrm{Rh})$ source with initial activity of $20 \mathrm{mCi}$ was used. The spectrometer was periodically calibrated using a natural iron foil as a standard.

\section{Results and Discussion}

\subsection{XRD and TEM Analysis}

The X-ray diffraction patterns of mixed spinel ferrites $\left(\mathrm{Mn}_{1.05} \mathrm{Zn}_{0.5} \mathrm{Al}_{x} \mathrm{Fe}_{1.9-x} \mathrm{O}_{4}\right.$ for $x=0.4,0.6,0.8$, and 1.0$)$ are displayed in Figure 1. The indexing of diffraction lines from various planes was assigned using JCPDS file no. 742

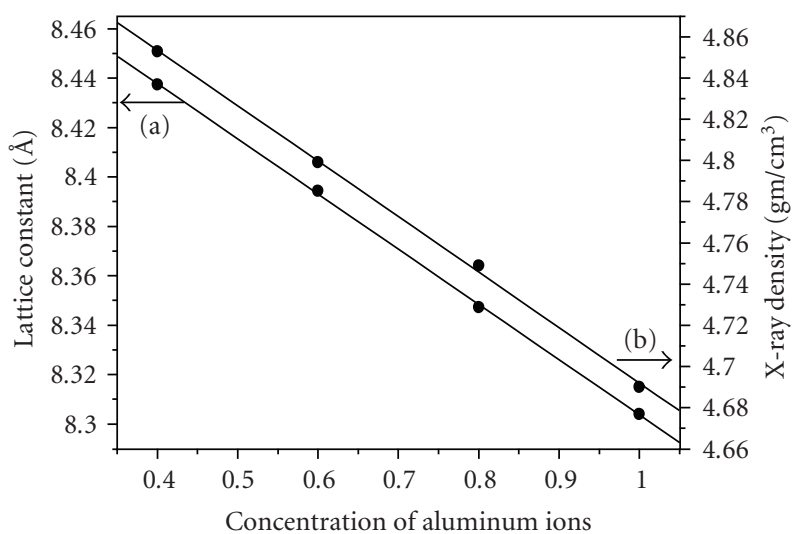

Figure 2: Variation of (a) lattice constant and (b) density with aluminum concentration.

435. All the samples were found to be face-centered cubic (FCC) with Fd-3m space group. The values of the lattice constant " $a_{0}$ " for all the samples determined from X-ray data are listed in Table 1 . The lattice constant " $a_{O}$ " is found to decrease linearly with aluminum concentration $(x)$ as shown in Figure 2(a), thereby obeying Vegard's law [14]. The decrease in lattice constant is attributed to the replacement of $\mathrm{Fe}^{3+}$ ions of larger ionic radius $(0.64 \AA)$ by smaller $\mathrm{Al}^{3+}$ ions $(0.50 \AA)$, which causes shrinking in the unit cell dimensions. The decrease in " $a_{O}$ " and the shift of reflections toward higher angle with the increasing aluminum concentration show that aluminum atoms have been incorporated into the spinel structure [15]. The bulk density of each sample was determined by Archimedes' principle and is listed in Table 1 . The X-ray density " $d_{x}$ " of each sample was calculated from the values of the lattice constant using the formula

$$
d_{x}=\frac{Z M}{N a_{O}^{3}}
$$

where " $Z$ " represents the number of molecules in a unit cell of the spinel lattice, $M$ the molecular weight of the ferrite samples, $N$ the Avogadro's number, and $a_{O}$ the lattice constant of the ferrite. The X-ray density decreases with increasing aluminum concentration $(x)$ and hence follows similar trend as that of lattice constant " $a_{O}$ " as shown in Figure 2(b). This is due to the fact that the decrease in mass (due to replacement of iron by aluminum) overtakes the decrease in volume of the unit cell. The percentage porosity of each sample was calculated using the relation:

$$
\text { Percentage porosity }(p \%)=\left[1-\frac{d}{d_{x}}\right] \times 100 \text {, }
$$

where notations have their usual meanings. The calculated values of the bulk density, X-ray density, and the percentage porosity of the present ferrite system are listed in Table 1 . The calculated values of the porosity are in good agreement with the values generally observed in ferrites prepared by solidstate reaction route $[12,16]$. 
TABLE 1: Lattice constant, density, porosity, and grain size for $\mathrm{Mn}_{1.05} \mathrm{Zn}_{0.05} \mathrm{Al}_{x} \mathrm{Fe}_{1.9-x} \mathrm{O}_{4}$ system.

\begin{tabular}{|c|c|c|c|c|c|c|c|}
\hline \multirow{2}{*}{$\begin{array}{l}\text { Composition } \\
(x)\end{array}$} & \multicolumn{2}{|c|}{ Lattice constant } & \multirow{2}{*}{$\begin{array}{c}\text { X-ray density } \\
\left(d_{x} \pm 0.002\right) \mathrm{gm} / \mathrm{cm}^{3}\end{array}$} & \multirow{2}{*}{$\begin{array}{c}\text { Bulk density } \\
(d \pm 0.002) \mathrm{gm} / \mathrm{cm}^{3}\end{array}$} & \multirow{2}{*}{$\begin{array}{c}\text { Porosity } \\
p \%\end{array}$} & \multicolumn{2}{|c|}{ Grain size $D( \pm 1 \mathrm{~nm})$} \\
\hline & $\left(a_{O} \pm 0.002\right) \AA$ & $\left(a_{t} \pm 0.002\right) \AA$ & & & & XRD & TEM \\
\hline 0.4 & 8.4374 & 8.473 & 4.853 & 4.516 & 6.944 & 46 & 45 \\
\hline 0.6 & 8.3943 & 8.426 & 4.799 & 4.498 & 6.272 & 37 & 35 \\
\hline 0.8 & 8.3472 & 8.379 & 4.749 & 4.469 & 5.896 & 32 & 30 \\
\hline 1.0 & 8.3041 & 8.332 & 4.690 & 4.385 & 6.503 & 28 & 25 \\
\hline
\end{tabular}

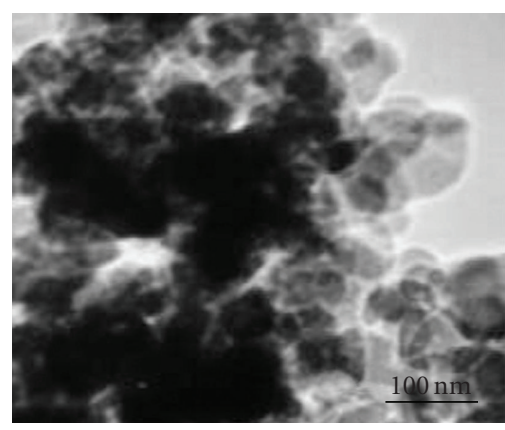

(a)

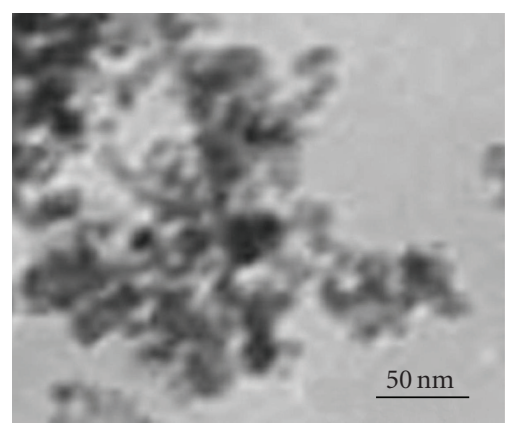

(b)

Figure 3: Transmission micrographs for $\mathrm{Mn}_{1.05} \mathrm{Zn}_{0.05} \mathrm{Al}_{x} \mathrm{Fe}_{1.9-x} \mathrm{O}_{4}$ (a) for $x=0.4$ and (b) for $x=1.0$.

The average grain size of all the samples is evaluated from the line broadening of the (311) peaks using Debye-Scherrer equation

$$
D_{(311)}=\frac{0.9 \lambda}{\beta_{1 / 2} \cos \theta},
$$

where " $D$ " is the average particle size of the crystallites, $\lambda$ is the wavelength of the incident $\mathrm{X}$-ray, $\theta$ is the corresponding Bragg angle, and $\beta_{1 / 2}$ is the full width at the half maximum (FWHM) of the (311) peak. The uncertainties in the particle size determination were estimated from the errors in the fitting procedures while fitting the 311 peak, which lie in the range $\pm 1 \mathrm{~nm}$. The average particle sizes of all the samples are listed in Table 1. The transmission electron micrographs of the ferrite nanoparticles are displayed in Figure 3. It has been observed that the particles prepared with smaller aluminum substitution displayed in Figure 3(a) are somewhat agglomerated in nature. The degree of agglomeration decreases with increase of aluminum substitution, the particles prepared from higher aluminum concentration; $x=1.0$ are discrete and somewhat spherical as shown in Figure 3(b). The decrease in agglomeration is due to the replacement of $\mathrm{Fe}^{3+}$ ions by $\mathrm{Al}^{3+}$ ions that leads to decrease in cation vacancies, which in turn decreases the grain size. The average particle sizes estimated from the TEM studies listed in Table 1 are in good agreement with those values obtained from XRD analysis using Debye-Scherrer equation.

The cation distribution in the various spinel ferrite systems has been estimated from X-ray diffraction, Mössbauer and Magnetization measurements [17-19]. It has been reported that the intensities of (220), (422), and (400) planes are sensitive to cations on tetrahedral (A-) and octahedral (B-) sites [20, 21]. Therefore, we have used the intensities of (220), (422), and (400) planes to determine the cation distribution. The relative X-ray diffraction intensity " $I_{h k l}$ " of a given diffraction line was calculated using the formula suggested by Buerger [22]

$$
I_{h k l}=\left|F_{h k l}\right|^{2} \cdot P \cdot L_{P},
$$

where $I_{h k l}$ is the relative integral intensity, $F_{h k l}$ the structure factor, $P$ the multiplicity factor, $L_{P}$ the Lorentz factor. The intensity ratios $\left(I_{220} / I_{400}\right.$ and $\left.I_{422} / I_{400}\right)$ have been considered to be more sensitive to the cation distribution [23]. It is known that $\mathrm{Fe}^{3+}$ and $\mathrm{Al}^{3+}$ ions distribute over $\mathrm{A}$ - and $\mathrm{B}$-sites [24], while $\mathrm{Mn}^{2+}$ and $\mathrm{Zn}^{2+}$ ions have strong preference for A-site [25-27]. The intensities corresponding to (220) and (422) reflections are most sensitive to cations on tetrahedral sites $[20,21]$, while those of (222) reflection to cation on octahedral sites [20]. Figure 1 shows that the intensities of (220), (422), and (222) reflections decrease with substitution of aluminum ions indicating that $\mathrm{Al}^{3+}$ ions enter in both octahedral (B-) and tetrahedral (A-) sites. Based on the above, intensity ratios: $I_{220} / I_{440}, I_{422} / I_{440}$, and $I_{440} / I_{400}$ for all the samples were calculated for various cation distributions. The calculated values, those closet to the experimental data, are given in Table 2. On the basis of estimated cation distribution (Table 2), the value of theoretical lattice constant " $a$ " for various compositions has been determined using the relation $[28,29]$

$$
a_{t}=\frac{8}{3 \sqrt{3}}\left(r_{\mathrm{A}}+r_{O}\right)+\sqrt{3}\left(r_{\mathrm{B}}+r_{O}\right),
$$


TABLE 2: Cation distribution data calculated from XRD pattern of the $\mathrm{Mn}_{1.05} \mathrm{Zn}_{0.05} \mathrm{Al}_{x} \mathrm{Fe}_{1.9-x} \mathrm{O}_{4}$ system.

\begin{tabular}{|c|c|c|c|c|c|c|c|c|}
\hline \multirow{3}{*}{ Composition } & \multicolumn{6}{|c|}{ X-ray intensity } & \multirow{3}{*}{ Cation distribution } & \multirow{3}{*}{$\begin{array}{l}\mathrm{Fe}^{3+}(\mathrm{B}) / \\
\mathrm{Fe}^{3+}(\mathrm{A})\end{array}$} \\
\hline & \multicolumn{2}{|c|}{$I_{220} / I_{440}$} & \multicolumn{2}{|c|}{$I_{422} / I_{440}$} & \multicolumn{2}{|c|}{$I_{440} / I_{400}$} & & \\
\hline & Exp. & Cal. & Exp. & Cal. & Exp. & Cal. & & \\
\hline $\mathrm{Mn}_{1.05} \mathrm{Zn}_{0.05} \mathrm{Al}_{0.4} \mathrm{Fe}_{1.5} \mathrm{O}_{4}$ & 1.1572 & 1.2823 & 0.8191 & 0.7236 & 1.5198 & 1.5278 & $\left(\mathrm{Fe}_{0.535} \mathrm{Zn}_{0.05} \mathrm{Mn}_{0.323} \mathrm{Al}_{0.092}\right)^{\mathrm{A}}\left[\mathrm{Fe}_{0.965} \mathrm{Mn}_{0.727} \mathrm{Al}_{0.308}\right]^{\mathrm{B}}$ & 1.80 \\
\hline $\mathrm{Mn}_{1.05} \mathrm{Zn}_{0.05} \mathrm{Al}_{0.6} \mathrm{Fe}_{1.3} \mathrm{O}_{4}$ & 1.1926 & 1.2993 & 0.8049 & 0.6847 & 1.5351 & 1.5693 & $\left(\mathrm{Fe}_{0.489} \mathrm{Zn}_{0.05} \mathrm{Mn}_{0.323} \mathrm{Al}_{0.138}\right)^{\mathrm{A}}\left[\mathrm{Fe}_{0.811} \mathrm{Mn}_{0.727} \mathrm{Al}_{0.462}\right]^{\mathrm{B}}$ & 1.65 \\
\hline $\mathrm{Mn}_{1.05} \mathrm{Zn}_{0.05} \mathrm{Al}_{0.8} \mathrm{Fe}_{1.1} \mathrm{O}_{4}$ & 1.2903 & 1.3401 & 0.6801 & 0.5849 & 1.6810 & 1.6528 & $\left(\mathrm{Fe}_{0.443} \mathrm{Zn}_{0.05} \mathrm{Mn}_{0.323} \mathrm{Al}_{0.184}\right)^{\mathrm{A}}\left[\mathrm{Fe}_{0.657} \mathrm{Mn}_{0.727} \mathrm{Al}_{0.616}\right]^{\mathrm{B}}$ & 1.48 \\
\hline $\mathrm{Mn}_{1.05} \mathrm{Zn}_{0.05} \mathrm{Al}_{1.0} \mathrm{Fe}_{0.9} \mathrm{O}_{4}$ & 1.5523 & 1.5700 & 0.5272 & 0.5091 & 1.7046 & 1.7501 & $\left(\mathrm{Fe}_{0.397} \mathrm{Zn}_{0.05} \mathrm{Mn}_{0.323} \mathrm{Al}_{0.230}\right)^{\mathrm{A}}\left[\mathrm{Fe}_{0.503} \mathrm{Mn}_{0.727} \mathrm{Al}_{0.770}\right]^{\mathrm{B}}$ & 1.26 \\
\hline
\end{tabular}

where $r_{\mathrm{A}}, r_{\mathrm{B}}$ are the radii of tetrahedral (A-) and octahedral (B-) sites, respectively, and $r_{O}$ is the radius of the oxygen ion $\mathrm{O}^{2-}(1.48 \AA)$. The calculated values " $a_{t}$ " are nearly equal to the experimental observed values " $a_{O}$ " and hence confirming that the estimated cation distribution is correct. The site radii $r_{\mathrm{A}}$ and $r_{\mathrm{B}}$ used above were determined from the following equation:

$$
\begin{aligned}
r_{\mathrm{A}}= & (0.627-0.23 x) r_{\mathrm{tet}} \mathrm{Fe}^{3+}+0.05 r_{\mathrm{tet}} \mathrm{Zn}^{2+} \\
& +0.323 r_{\text {tet }} \mathrm{Mn}^{2+}+0.23 x r_{\text {tet }} \mathrm{Al}^{3+}, \\
r_{\mathrm{B}}= & (1.273-0.77 x) r_{\mathrm{oct}} \mathrm{Fe}^{3+}+0.727 r_{\mathrm{oct}} \mathrm{Mn}^{2+} \\
& +0.77 x r_{\mathrm{oct}} \mathrm{Al}^{3+} .
\end{aligned}
$$

The calculated values of $r_{\mathrm{A}}$ and $r_{\mathrm{B}}$ are listed in Table 3 . The value of $r_{\mathrm{A}}$ decreases slowly; however the value of $r_{\mathrm{B}}$ decreases noticeably with increasing aluminum concentration. This is due to the substitution process and the distribution of cations amongst the tetrahedral (A-) and octahedral (B-) sites. The value of the oxygen positional parameter " $u$ " is calculated by using the following relation $[28,29]$ :

$$
r_{\mathrm{A}}=a_{O} \sqrt{3}(u-0.25)-r_{O}
$$

The calculated values of " $u$ " are listed in Table 3 . The values of the tetrahedral $\left(d_{\mathrm{AL}}\right)$, octahedral bond lengths $\left(d_{\mathrm{BL}}\right)$, tetrahedral edge length $\left(d_{\mathrm{AE}}\right)$, shared $\left(d_{\mathrm{BE}}\right)$ and unshared octahedral edge lengths $\left(d_{\mathrm{BEU}}\right)$ are calculated by using the experimental values of lattice constant " $a_{O}$ " and oxygen positional parameter " $u$ " from the following equations [28, 29]:

$$
\begin{aligned}
d_{\mathrm{AL}} & =a_{O} \sqrt{3}(u-0.25), \\
d_{\mathrm{BL}} & =a_{O} \sqrt{\left(3 u^{2}-\frac{11}{4} u+\frac{43}{64}\right)}, \\
d_{\mathrm{AE}} & =a_{O} \sqrt{2}(2 u-0.5), \\
d_{\mathrm{BE}} & =a_{O} \sqrt{2}(1-2 u), \\
d_{\mathrm{BEU}} & =a_{O} \sqrt{\left(4 u^{2}-3 u+\frac{11}{16}\right)} .
\end{aligned}
$$

The calculated values of the above X-ray parameters are listed in Table 3 . It is observed that $d_{\mathrm{AL}}, d_{\mathrm{BL}}, d_{\mathrm{AE}}, d_{\mathrm{BE}}$, and $d_{\mathrm{BEU}}$ decrease with increasing aluminum concentration $(x)$. This is attributed to the substitution process and the cation distribution, especially the replacement of $\mathrm{Fe}^{3+}$ larger ions at $\mathrm{B}$ - and $\mathrm{A}$-sites with smaller $\mathrm{Al}^{3+}$ ions. These results are in good agreement with the results reported earlier [30]. It has been reported that the jump length " $L$ " (the distance between the magnetic ions) of electrons influences the physical properties of the ferrite system [31]. Electrons that are hopping between B- and A-sites are less probable compared to those between B- and B-sites because the distance between the two metal ions placed at B-sites is smaller than the distance if they are placed one at B-sites and the other at A-sites $[32,33]$. The jump length " $L$ " of the tetrahedral (A-) and octahedral (B-) sites is determined from the following relation $[34,35]$ :

$$
\begin{aligned}
& L_{\mathrm{A}}=a_{O} \frac{\sqrt{3}}{4}, \\
& L_{\mathrm{B}}=a_{O} \frac{\sqrt{2}}{4} .
\end{aligned}
$$

The calculated values of jump length " $L$ " of A- and B-sites are shown in Table 3 . It is evident from Table 3 that the jump length " $L$ " decreases with increasing $\mathrm{Al}^{3+}$ concentration $(x)$ and behaves similarly as that of lattice constant. The decrease in jump length is due to the replacement of $\mathrm{Fe}^{3+}$ ions of larger ionic radius with $\mathrm{Al}^{3+}$ ions of smaller ionic radius from A- and B-sites, causing a decrease in distance between the magnetic ions. Pandit et al. [23] and Amer [30] have reported similar results that the introduction of smaller ions on the Aand $\mathrm{B}$-sites decreases the distance between the magnetic ions.

\subsection{Mössbauer Measurements}

${ }^{57} \mathrm{Fe}$ Mössbauer absorption spectra of mixed spinel ferrite system, $\mathrm{Mn}_{1.05} \mathrm{Zn}_{0.05} \mathrm{Al}_{x} \mathrm{Fe}_{1.9-x} \mathrm{O}_{4} ; x=0.4,0.6,0.8$, and 1.0, recorded at room temperature are displayed in Figure 4. The experimental data were fitted using NORMOS/SITE program [36]. Each spectrum exhibits a superposition of two Zeeman sextets. Outer sextet corresponding to a higher magnetic field is attributed to $\mathrm{Fe}^{3+}$ ions on the octahedral $\mathrm{B}$-site and the inner sextet corresponding to lower magnetic field is attributed to $\mathrm{Fe}^{3+}$ ions on the tetrahedral A-site. The computed values of the hyperfine parameters are listed in Table 4 . In the present ferrite system, the value of isomer shift $(\delta)$ of B-site is greater than A-site and is in agreement with 
TABLE 3: X-ray parameters (error bar $\pm 0.002 \AA$ ) tetrahedral and octahedral bond lengths ( $d_{\mathrm{AL}}$ and $\left.d_{\mathrm{BL}}\right)$, jump lengths $\left(L_{\mathrm{A}}\right.$ and $\left.L_{\mathrm{B}}\right)$, tetrahedral edge $d_{\mathrm{AE}}$, and shared and unshared octahedral edge lengths ( $d_{\mathrm{BE}}$ and $\left.d_{\mathrm{BEU}}\right)$.

\begin{tabular}{lcccccccccc}
\hline $\begin{array}{l}\text { Composition } \\
(x)\end{array}$ & $\begin{array}{c}d_{\mathrm{AL}} \\
(\AA)\end{array}$ & $\begin{array}{c}d_{\mathrm{BL}} \\
(\AA)\end{array}$ & $\begin{array}{c}d_{\mathrm{AE}} \\
(\AA)\end{array}$ & $\begin{array}{c}d_{\mathrm{BE}} \\
(\AA)\end{array}$ & $\begin{array}{c}d_{\mathrm{BEU}} \\
(\AA)\end{array}$ & $\begin{array}{c}L_{\mathrm{A}} \\
(\AA)\end{array}$ & $\begin{array}{c}L_{\mathrm{B}} \\
(\AA)\end{array}$ & $\begin{array}{c}r_{\mathrm{A}} \\
(\AA)\end{array}$ & $\begin{array}{c}r_{\mathrm{B}} \\
(\AA)\end{array}$ & $\begin{array}{c}u \\
(\AA)\end{array}$ \\
\hline 0.4 & 2.1687 & 1.9314 & 3.5415 & 2.4246 & 3.0045 & 3.6535 & 2.9830 & 0.6892 & 1.3562 & 0.3984 \\
0.6 & 2.1620 & 1.9178 & 3.5304 & 2.4051 & 2.9938 & 3.6348 & 2.9670 & 0.6833 & 1.3363 & 0.3987 \\
0.8 & 2.1569 & 1.9053 & 3.5226 & 2.3798 & 2.9782 & 3.6144 & 2.9512 & 0.6774 & 1.3162 & 0.3992 \\
1.0 & 2.1503 & 1.8936 & 3.5112 & 2.3604 & 2.9640 & 3.5958 & 2.9359 & 0.6713 & 1.2962 & 0.3995 \\
\hline
\end{tabular}

TABLE 4: Room temperature Mössbauer effect parameters for $\mathrm{Mn}_{1.05} \mathrm{Zn}_{0.05} \mathrm{Al}_{x} \mathrm{Fe}_{1.9-x} \mathrm{O}_{4}$ system as a function of $x$.

\begin{tabular}{|c|c|c|c|c|c|}
\hline $\begin{array}{l}\text { Composition } \\
(x)\end{array}$ & Site & $\begin{array}{c}\text { Isomer shift }^{*} \\
(\delta \pm 0.01) \mathrm{mm} / \mathrm{s}\end{array}$ & $\begin{array}{l}\text { Quadrupole splitting } \\
\qquad(\Delta \pm 0.01) \mathrm{mm} / \mathrm{s}\end{array}$ & $\begin{array}{c}H_{\mathrm{hfs}} \\
( \pm 1.0 \mathrm{~T})\end{array}$ & $\begin{array}{c}\mathrm{Fe}^{3+}(\mathrm{B}) / \mathrm{Fe}^{3+}(\mathrm{A}) \\
(\%)\end{array}$ \\
\hline \multirow{2}{*}{0.4} & B & 0.18 & 0.00 & 42.1 & \multirow{2}{*}{1.79} \\
\hline & A & 0.15 & 0.00 & 39.5 & \\
\hline \multirow{2}{*}{0.6} & B & 0.17 & 0.00 & 40.3 & \multirow{2}{*}{1.63} \\
\hline & A & 0.15 & 0.00 & 37.4 & \\
\hline \multirow{2}{*}{0.8} & B & 0.16 & 0.00 & 39.0 & \multirow{2}{*}{1.44} \\
\hline & A & 0.14 & 0.00 & 35.1 & \\
\hline \multirow{2}{*}{1.0} & B & 0.17 & 0.00 & 37.8 & \multirow{2}{*}{1.21} \\
\hline & A & 0.16 & 0.00 & 33.1 & \\
\hline
\end{tabular}

* Isomer shift given relative to $\alpha$-Fe.

the reported data. This is due to the large band separation of $\mathrm{Fe}^{3+}-\mathrm{O}^{2-}$ for the B-site ions compared to A-site ions. It is observed that on increasing the $\mathrm{Al}^{3+}$ ions concentration $(x)$, the value of isomer shift of the A- and B-sites do not show any appreciable change, indicating that the s-electron distribution of $\mathrm{Fe}^{3+}$ ions is hardly influenced by $\mathrm{Al}^{3+}$ substitution. Furthermore, the observed values of isomer shift $(\delta)$ are significantly less than the expected value, $0.5 \mathrm{~mm} / \mathrm{s}$ for the $\mathrm{Fe}^{2+}$ ions [17]. Hence the presence of $\mathrm{Fe}^{2+}$ ions in the present ferrite system is ruled out. Thus the electron exchange interaction $\left(\mathrm{Fe}^{2+} \leftrightarrow \mathrm{Fe}^{3+}+\mathrm{e}^{-}\right)$does not occur and hence the oxidation state of $\mathrm{Fe}^{3+}$ remains unchanged during synthesis process. The hyperfine field $H_{\mathrm{hfs}}$ values at B- and A-sites show a gradual monotonic decrease with increasing aluminum ion concentration $(x)$. This is because of supertransferred hyperfine field at the central cation that originates from the magnetic moments of the nearest-neighbor cations, that is, from the intrasublattice contributions $h_{\mathrm{AA}}$ and $h_{\mathrm{BB}}$ and the inter sublattice contributions $h_{\mathrm{AB}}$ and $h_{\mathrm{BA}}$. In the present ferrite system, under study, the intersulattice contributions $h_{\mathrm{AB}}$ and $h_{\mathrm{BA}}$ are predominant. The introduction of $\mathrm{Al}^{3+}$ ions replaces $\mathrm{Fe}^{3+}$ ions from the $\mathrm{A}$ - and $\mathrm{B}$-sites and decreases inter sublattice contributions, which in turn decreases the hyperfine field $H_{\mathrm{hfs}}$ at both A- and B-sites. As nonmagnetic $\mathrm{Al}^{3+}$ ions replaces $\mathrm{Fe}^{3+}$ ions, the correct amount of $\mathrm{Fe}^{3+}$ present at $\mathrm{A}$ - and $\mathrm{B}$-sites is estimated by determining the area under the Mössbauer absorption. The correct amount of $\mathrm{Fe}^{3+}$ ions occupied by octahedral (B-) and tetrahedral (A-) sites obtained from the Mössbauer absorption spectra and those calculated on the basis of cation distribution are in good agreement. The $\mathrm{Fe}^{3+}(\mathrm{B}) / \mathrm{Fe}^{3+}(\mathrm{A})$ ratio obtained from the Mössbauer spectra and X-ray intensity calculations

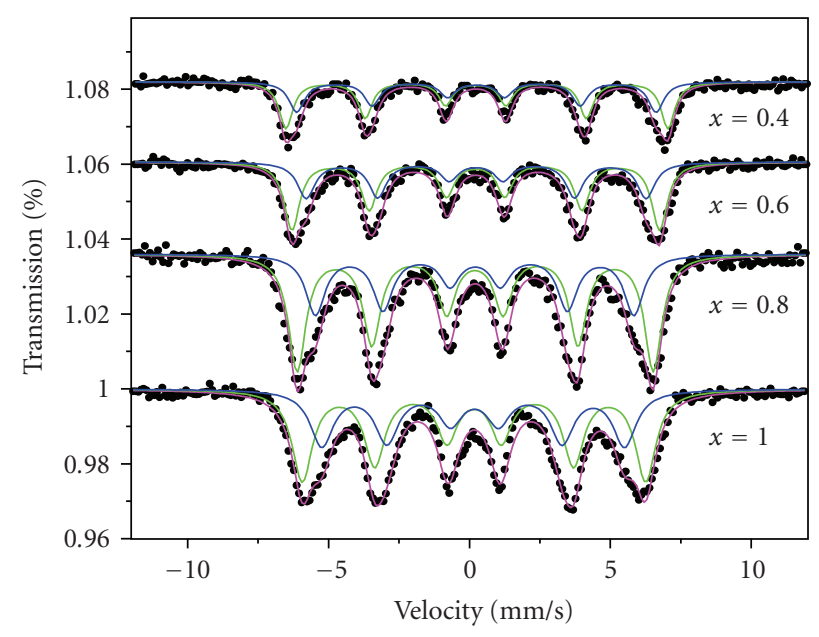

Figure 4: Room temperature Mössbauer absorption spectra of $\mathrm{Mn}_{1.05} \mathrm{Zn}_{0.05} \mathrm{Al}_{x} \mathrm{Fe}_{1.9-x} \mathrm{O}_{4}$ for $x=0.4,0.6,0.8$, and 1.0.

decreases with increasing aluminum concentration suggesting the decrease in ferrimagnetic behavior. With increase of $\mathrm{Al}^{3+}$ ions concentration, intensity and the line width of the Mössbauer spectra increases indicating a reduction in particle size and is in accordance with TEM measurements. These results are in consistent with the results reported earlier [13].

\section{Conclusion}

The substitution of $\mathrm{Al}^{3+}$ ions in $\mathrm{Mn}_{1.05} \mathrm{Zn}_{0.5} \mathrm{Al}_{x} \mathrm{Fe}_{1.9-x} \mathrm{O}_{4}$ system leads to the formation of nanosized mixed spinel 
ferrites with particle size $46 \mathrm{~nm}$ to $28 \mathrm{~nm}$. The unit cell parameter decreases linearly with the increase of aluminum concentration due to its small ionic radius. The cation distribution has been determined from X-ray intensity ratios of various planes and hence verified by comparing the theoretical lattice parameter with experimental observed lattice parameter. It is observed that the correct amount of $\mathrm{Fe}^{3+}$ ions occupied by $\mathrm{B}$ - and A-sites obtained from Mössbauer spectra are in good agreement with the values determined from X-ray intensity calculations for various $\mathrm{Al}^{3+}$ ions concentration. The Hyperfine magnetic field obtained from the Mössbauer absorption spectra decreases with increasing aluminum concentration suggesting the decrease in ferrimagnetic behavior and has been explained on the basis of super transferred hyperfine fields. The Xray parameters, for example, lattice constant, X-ray density, bulk density, ionic radius, bond length, jump length of the Aand B-sites, oxygen positional parameter, A-site edge length, shared and unshared B-site edge lengths were determined and found affected by the $\mathrm{Al}^{3+}$ ions substitution.

\section{Acknowledgments}

The first author is grateful to Dr. Alok Banerjee and Dr. R. J. Chaudhary, scientists, UGC-DAE, Consortium for Scientific Research, University Campus, Khandwa Road, Indore (M.P.), India for providing experimental facilities.

\section{References}

[1] R. Justin Joseyphus, A. Narayanasamy, K. Shinoda, B. Jeyadevan, and K. Tohji, "Synthesis and magnetic properties of the size-controlled $\mathrm{Mn}-\mathrm{Zn}$ ferrite nanoparticles by oxidation method," Journal of Physics and Chemistry of Solids, vol. 67, no. 7, pp. 1510-1517, 2006.

[2] Q. A. Pankhurst, J. Connolly, S. K. Jones, and J. Dobson, "Applications of magnetic nanoparticles in biomedicine," Journal of Physics D, vol. 36, no. 13, pp. R167-R181, 2003.

[3] R. Jurgons, C. Seliger, A. Hilpert, L. Trahms, S. Odenbach, and C. Alexiou, "Drug loaded magnetic nanoparticles for cancer therapy," Journal of Physics: Condensed Matter, vol. 18, no. 38, pp. S2893-S2902, 2006.

[4] A. C. F. M. Costa, E. Tortella, M. R. Morelli, and R. H. G. A. Kiminami, "Synthesis, microstructure and magnetic properties of Ni-Zn ferrites," Journal of Magnetism and Magnetic Materials, vol. 256, no. 1-3, pp. 174-182, 2003.

[5] A. Verma, T. C. Goel, R. G. Mendiratta, and M. I. Alam, "Dielectric properties of NiZn ferrites prepared by the citrate precursor method," Materials Science and Engineering B, vol. 60, no. 2, pp. 156-162, 1999.

[6] C. Rath, S. Anand, R. P. Das, et al., "Dependence on cation distribution of particle size, lattice parameter, and magnetic properties in nanosize $\mathrm{Mn}-\mathrm{Zn}$ ferrite," Journal of Applied Physics, vol. 91, no. 3, pp. 2211-2215, 2002.

[7] C. Upadhyay, H. C. Verma, C. Rath, et al., "Mössbauer studies of nanosize $\mathrm{Mn}_{1-x} \mathrm{Zn}_{x} \mathrm{Fe}_{2} \mathrm{O}_{4}$," Journal of Alloys and Compounds, vol. 326, no. 1-2, pp. 94-97, 2001.

[8] E. E. Sileo, R. Rotelo, and S. E. Jacobo, "Nickel zinc ferrites prepared by the citrate precursor method," Physica B, vol. 320, no. 1-4, pp. 257-260, 2002.
[9] R. A. Dunlap, A. Alghamdi, J. W. O’Brien, and S. J. Penney, “A Mössbauer effect investigation of superparamagnetic behavior in ball milled Mn-Zn ferrites," Journal of Alloys and Compounds, vol. 365, no. 1-2, pp. 84-88, 2004.

[10] S. K. Kulshreshtha and G. Ritter, "Mössbauer study of $\mathrm{Li}_{0.5} \mathrm{Fe}_{2.5-x} \mathrm{Al}_{x} \mathrm{O}_{4}$ : cation distribution and noncollinear spin alignment," Journal of Materials Science, vol. 20, no. 3, pp. 821826, 1985.

[11] A. A. Choni, A. I. Etyhhand, and A. A. Mohamed, in Proceeding of the International Conference on Ferrites (ICF '80), p. 216, Kyoto, Japan, September-October 1980.

[12] S. Mishra, T. K. Kundu, K. C. Barick, D. Bahadur, and D. Chakravorty, "Preparation of nanocrystalline $\mathrm{MnFe}_{2} \mathrm{O}_{4}$ by doping with $\mathrm{Ti}^{4+}$ ions using solid-state reaction route," Journal of Magnetism and Magnetic Materials, vol. 307, no. 2, pp. 222226, 2006.

[13] S. S. Ata-Allah and M. Kaiser, "Cation distribution, hyperfine parameters and conduction mechanism in the ferrimagnetic system $\mathrm{Cu}_{0.5} \mathrm{Co}_{0.5} \mathrm{Ga}_{x} \mathrm{Fe}_{2-x} \mathrm{O}_{4}$," Physica Status Solidi B, vol. 242, no. 6, pp. 1324-1335, 2005.

[14] C. G. Whinfrey, D.W. Eckort, and A. Tauber, "Preparation and X-ray diffraction data for some rare earth stannates," Journal of the American Chemical Society, vol. 82, no. 11, pp. 2695-2697, 1960.

[15] J. A. Toledo, M. A. Valenzuela, P. Bosch, et al., "Effect of $\mathrm{AI}^{3+}$ introduction into hydrothermally prepared $\mathrm{ZnFe}_{2} \mathrm{O}_{4}$," Applied Catalysis A, vol. 198, no. 1-2, pp. 235-245, 2000.

[16] K. Latha and D. Ravinder, "Electrical-conductivity of MnZn ferrites," Physica Status Solidi A, vol. 139, pp. K109-K112, 1993.

[17] K. P. Thummer, M. C. Chhantbar, K. B. Modi, G. J. Baldha, and H. H. Joshi, "Localized canted spin behaviour in $\mathrm{Zn}_{x} \mathrm{Mg}_{1.5-x} \mathrm{Mn}_{0.5} \mathrm{FeO}_{4}$ spinel ferrite system," Journal of Magnetism and Magnetic Materials, vol. 280, no. 1, pp. 23-30, 2004.

[18] A. Rais, A. M. Gismelseed, and I. A. Al-Omari, "Cation distribution and magnetic properties of nickel-chromium ferrites $\mathrm{NiCr}_{x} \mathrm{Fe}_{2-x} \mathrm{O}_{4}(0 \leq x \leq 1.4)$," Physica Status Solidi $B$, vol. 242, no. 7, pp. 1497-1503, 2005.

[19] S. Singhal, J. Singh, S. K. Barthwal, and K. Chandra, "Preparation and characterization of nanosize nickel-substituted cobalt ferrites $\left(\mathrm{Co}_{1-x} \mathrm{Ni}_{x} \mathrm{Fe}_{2} \mathrm{O}_{4}\right)$," Journal of Solid State Chemistry, vol. 178, no. 10, pp. 3183-3189, 2005.

[20] E. Wolska, E. Riedel, and W. Wolski, "The evidence of $\mathrm{Cd}_{x}{ }^{2+} \mathrm{Fe}_{1-x}{ }^{3+}\left[\mathrm{Ni}_{1-x}{ }^{2+} \mathrm{Fe}_{1+x}{ }^{3+}\right] \mathrm{O}_{4}$ cation distribution based on X-ray and Mössbauer data," Physica Status Solidi A, vol. 132, no. 1, pp. K51-K56, 1992.

[21] B. P. Ladgaonkar and A. S. Vaingankar, "X-ray diffraction investigation of cation distribution in $\mathrm{Cd}_{x} \mathrm{Cu}_{1-x} \mathrm{Fe}_{2} \mathrm{O}_{4}$ ferrite system," Materials Chemistry and Physics, vol. 56, no. 3, pp. 280-283, 1998.

[22] M. G. Buerger, Crystal Structure Analysis, Wiley Interscience, New York, NY, USA, 1960.

[23] A. A. Pandit, A. R. Shitre, D. R. Shengule, and K. M. Jadhav, "Magnetic and dielectric properties of $\mathrm{Mg}_{1+x} \mathrm{Mn}_{x}, \mathrm{Fe}_{2-2 x}, \mathrm{O}_{4}$ ferrite system," Journal of Materials Science, vol. 40, no. 2, pp. 423-428, 2005.

[24] R. G. Kulkarni, B. S. Trivedi, H. H. Joshi, and G. J. Baldha, "Magnetic properties of copper ferrite aluminates," Journal of Magnetism and Magnetic Materials, vol. 159, no. 3, pp. 375380, 1996.

[25] J.M. Hatings and L. M. Corliss, "Neutron diffraction study of manganese ferrite," Physical Review, vol. 104, pp. 328-331, 1956. 
[26] G. A. Sawatzky, F. Van der Woude, and A. H. Morrish, "Note on cation distribution of $\mathrm{MnFe}_{2} \mathrm{O}_{4}$," Physics Letters A, vol. 25, no. 2, pp. 147-148, 1967.

[27] F. S. Li, L. Wang, J. B. Wang, et al., "Site preference of Fe in nanoparticles of $\mathrm{ZnFe}_{2} \mathrm{O}_{4}$," Journal of Magnetism and Magnetic Materials, vol. 268, no. 3, pp. 332-339, 2004.

[28] A. A. Yousif, M. E. Elzain, S. A. Mazen, H. H. Sutherland, M. H. Abdalla, and S. F. Masour, "Moessbauer and X-ray diffraction investigation of Li-Ti ferrites," Journal of Physics: Condensed Matter, vol. 6, no. 29, pp. 5717-5724, 1994.

[29] M. A. Amer, " ${ }^{57} \mathrm{Fe}$ Mössbauer, infrared and X-ray studies of the system $\mathrm{Zn}_{1-\mathrm{x}} \mathrm{Cu}_{\mathrm{x}} \mathrm{Cr}_{0.8} \mathrm{Fe}_{1.2} \mathrm{O}_{4}$," Physica Status Solidi A, vol. 181, no. 2, pp. 539-550, 2000.

[30] M. A. Amer, "Mössbauer, infrared, and X-ray studies of Tidoped $\mathrm{CoCr}_{1.2} \mathrm{Fe}_{0.8} \mathrm{O}_{4}$ ferrites," Physica Status Solidi B, vol. 237, no. 2, pp. 459-471, 2003.

[31] M. El-Saadawy and M. M. Barakat, "Effect of jump length of electrons on the physical properties of Mn-doped $\mathrm{CoCr}_{1.2} \mathrm{Fe}_{0.8} \mathrm{O}_{4}$ ferrites," Journal of Magnetism and Magnetic Materials, vol. 213, no. 3, pp. 309-311, 2000.

[32] K. Standley, Oxide Materials, Clarendon Oxford, Oxford, UK, 1972.

[33] K. H. Rao, S. B. Raju, K. Aggarwal, and R. G. Mendiratta, "Effect of Cr impurity on the dc resistivity of Mn-Zn ferrites," Journal of Applied Physics, vol. 52, no. 3, pp. 1376-1379, 1981.

[34] A. Globus, H. Pascard, and V. Cagan, "Distance between magnetic ions and fundamental properties in ferrites," Journal de Physique, vol. 38, no. C1, pp. 163-168, 1977.

[35] B. Gillot and F. Jemmali, "Dependence of electrical properties in iron-cobalt, iron-zinc ferrites near stoichiometry on firing tmeperatures and atmosphere," Physica Status Solidi A, vol. 76, no. 2, pp. 601-608, 1983.

[36] R. A. Brand, Laboratorium Fuer Angewandte Physik, Universitaet Duisburg, Lotharstr 1, D-4100 Duisburg 1. 

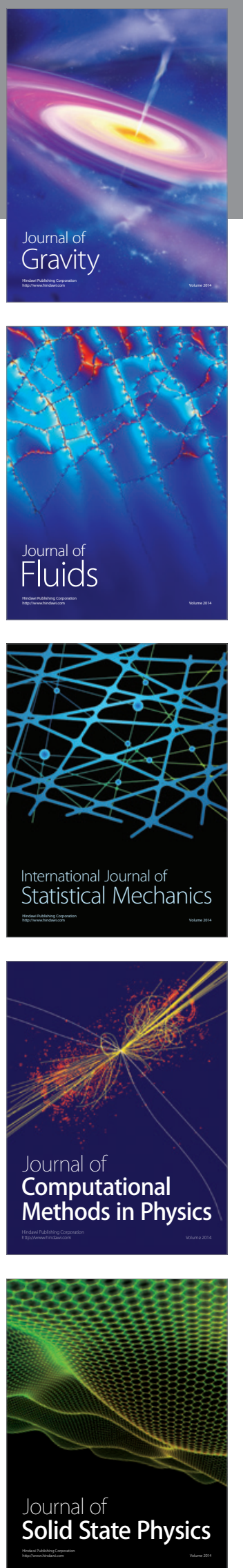

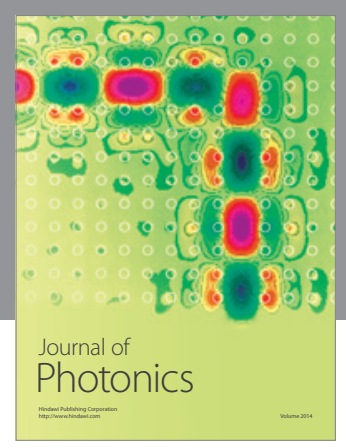

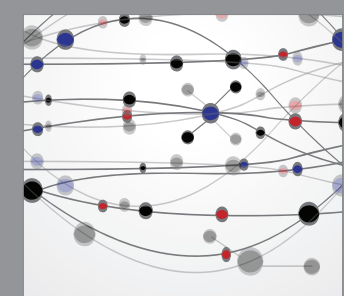

The Scientific World Journal
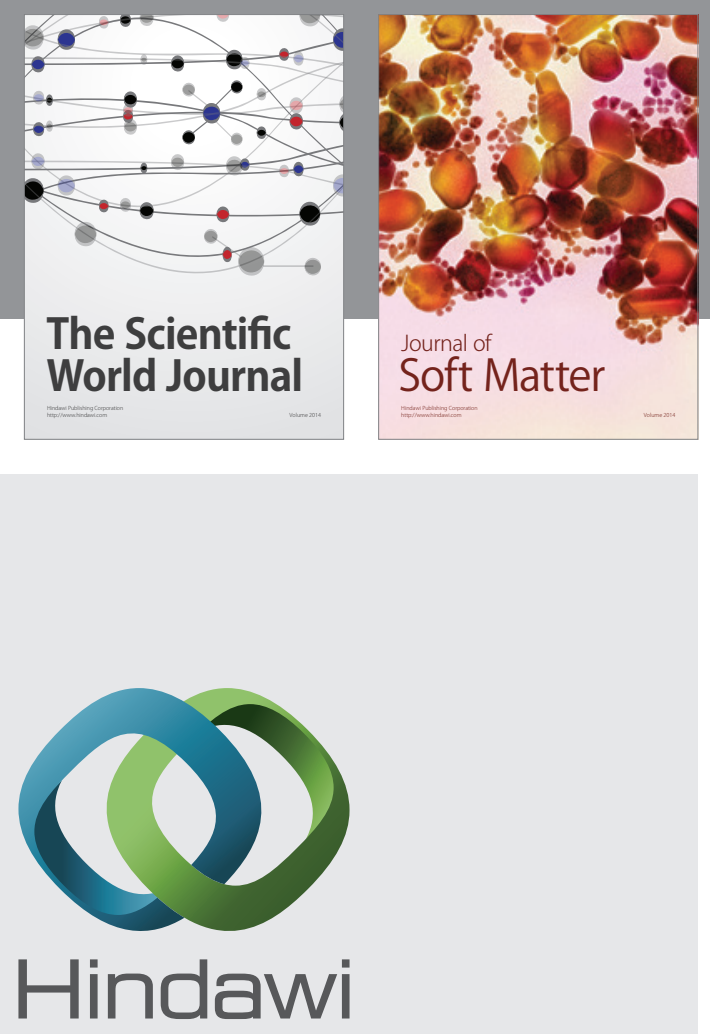

Submit your manuscripts at

http://www.hindawi.com
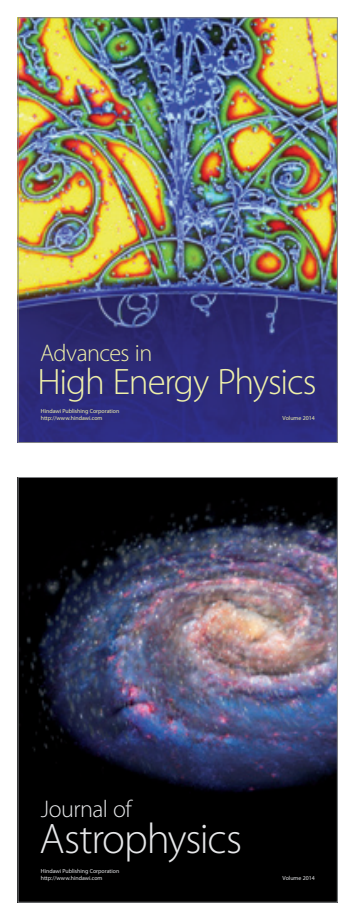
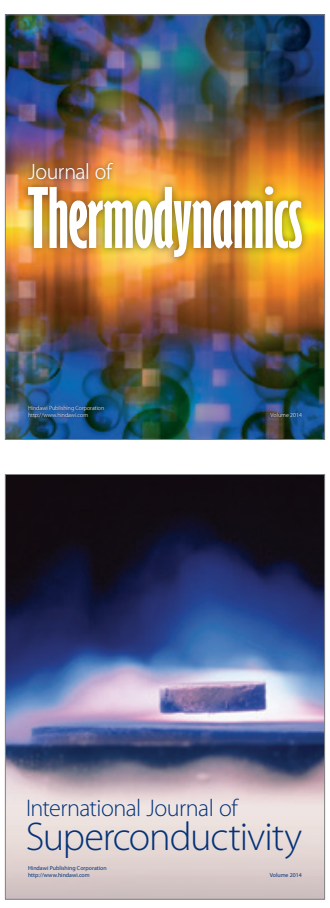
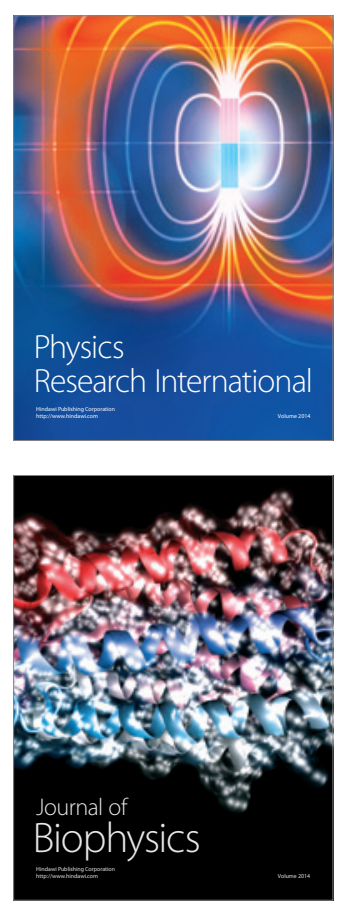
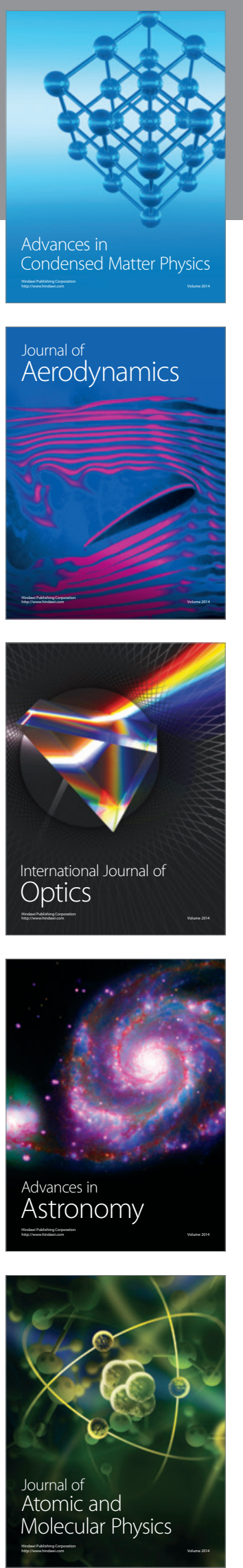